\title{
Electronmicroscopy studies on the bactericidal action of inflammatory leukocytes in murine salmonellosis
}

\author{
YAN-NIE GUO, H. S. HSU*, V. R. MUMAW' and IRENE NAKONECZNAT
}

Departments of Microbiology and Immunology and of $\dagger$ Pathology, Medical Callege of Virginia, Virginia Commonwealth University, Richmond, Virginia 23298 USA

\begin{abstract}
Summary. Inbred female $\mathrm{C} 3 \mathrm{H}$ mice were given $2 \times 10^{7} \mathrm{cfu}$ virulent Salmonella typhimurium by intraperitoneal injection. Peritoneal washings were harvested between $3 \mathrm{~h}$ and $72 \mathrm{~h}$ after infection and examined by electronmicroscopy. There was evidence of intracellular killing by polymorphs and macrophages. The degeneration of intracellular salmonellae was seen initially as enlarging central electron-lucent areas in the cytoplasm and peripheral condensation of cytoplasmic granules, followed by disruption of the bacterial envelope and disintegration of cellular structure. Alternatively, the initial injury appeared as an irregular and discontinuous bacterial envelope with compression of the bacterium and diffuse condensation of cytoplasmic granules. It was also evident that virulent salmonellae multiplied extracellularly in the peritoneal cavity of the infected mice.
\end{abstract}

\section{Introduction}

During the past decade, there has been controversy about whether pathogenic salmonellae survive and multiply within host phagocytes. Descriptions of these organisms as facultative intracellular parasites (Suter and Ramseier, 1964; Collins, 1974) imply that they are able to survive or multiply, particularly within host macrophages. They were based upon the results of cell-culture experiments (Mitsuhashi et al., 1961; Sato et al., 1962; Mackaness et al., 1966) which were later considered unreliable and were based on the misconception that an increased bacterial population within the liver and spleen of infected mice inevitably reflected intracellular bacterial multiplication (Collins, 1974). We have consistently been able to show by quantitative recovery of viable intracellular bacteria in cell culture that virulent Salmonella typhimurium and $S$. enteritidis are inactivated by macrophages from peritoneal exudates of guinea-pigs and mice (Hsu and Mayo, 1973; Rhodes and Hsu, 1974; Marecki et al., 1975; Mayo et al., 1977). This observation is supported by more recent reports by other investigators which show the intracellular killing of salmonellae within macrophages (van Zwet et al., 1975; Briles et al., 1981) as well as within

Received 29 Nov. 1984; accepted $30 \mathrm{Apr} .1985$.

* Correspondence should be addressed to Dr H. S. Hsu, Department of Microbiology and Immunology, Medical College of Virginia, Richmond, Virginia 23298 USA. polymorphs (Beckerdite et al., 1974; Rest et al., 1978; Modrzakowski and Spitznagel, 1979). Carrol et al. (1979) have also examined cultured mouse peritoneal macrophages by electronmicroscopy $1 \mathrm{~h}$ after infection with $S$. typhimurium and described evidence of damage to the ingested bacteria.

The assays of intracellular destruction of salmonellae in most of these studies were based on a decrease in viable bacteria in a population of phagocytes and the experiments were usually done in vitro. Such methodology is subject to criticism and many workers remain sceptical about the conclusion that salmonellae are killed intracellularly. Advances in the elucidation of the mechanism of host immunity, and hence the development of vaccines for salmonellosis, are hampered by the lack of knowledge about whether virulent salmonellae are killed or multiply within host cells and where the pathogen proliferates in host tissues. The present investigation concerns the interaction between the pathogen and individual phagocytes at the site of infection. We used electronmicroscopy to provide a sequential description of the degenerative changes of salmonellae in the inflammatory cells of mice from a very early stage after an infectious challenge.

\section{Materials and methods}

\section{Bacteria and growth conditions}

A virulent strain of Salmonella typhimurium SR-11 was used. The bacteria were propagated in Tryptic Soy Broth 
(TSB; Difco Laboratories, Detroit, MI) for $6 \mathrm{~h}$ and were then washed in saline as previously described (Hsu and Radcliffe, 1968). The optically standardized bacterial suspension contained approximately $2.5 \times 10^{9}$ viable organisms $/ \mathrm{ml}$.

\section{Mice}

Three-month-old female mice of the inbred strain $\mathrm{C} 3 \mathrm{H} /$ HeNMTV (Litton Bionetics, Charleston, SC) were used. They were highly susceptible to challenge with $S$. typhimurium; the LD50 was $<10^{2}$ bacteria by intraperitoneal (ip) inoculation.

\section{Infection of mice and harvesting of peritoneal exu- dates}

Groups of 15-18 mice were each given $2 \times 10^{7}$ salmonellae suspended in $0.2 \mathrm{ml}$ of saline by ip injection. At intervals of $3,7,24,30,48,54$ and $72 \mathrm{~h}$ after inoculation, two or three mice were killed with chloroform and immediately placed on a flat tray and their external skin was removed. About $6-8 \mathrm{ml}$ of chilled Hanks's solution containing heparin $6 \mathrm{U} / \mathrm{ml}$ were injected into the peritoneal cavity of each mouse with a syringe and 18-gauge needle and 3-4 min later a small incision was made on the abdominal wall through which a glass tube with multiple small openings was inserted. The peritoneal washings were gently stirred, removed by suction and transferred into a 15 -ml centrifuge tube containing $7 \mathrm{ml}$ of chilled glutaraldehyde $4 \%$ in $0.1 \mathrm{~m}$ sodium cacodylate buffer and placed in an ice bath. After $1 \mathrm{~h}$, the tubes were centrifuged at $1300 \mathrm{~g}$ for $20 \mathrm{~min}$ to collect the peritoneal exudate cells (PEC) and extracellular bacteria. The pellet was resuspended in $1.5 \mathrm{ml}$ of cacodylate buffer and the suspension was then allowed to stand for $5 \mathrm{~min}$ for the large clumps of tissue debris to sediment. The supernate containing PEC and extracellular bacteria was transferred to another tube.
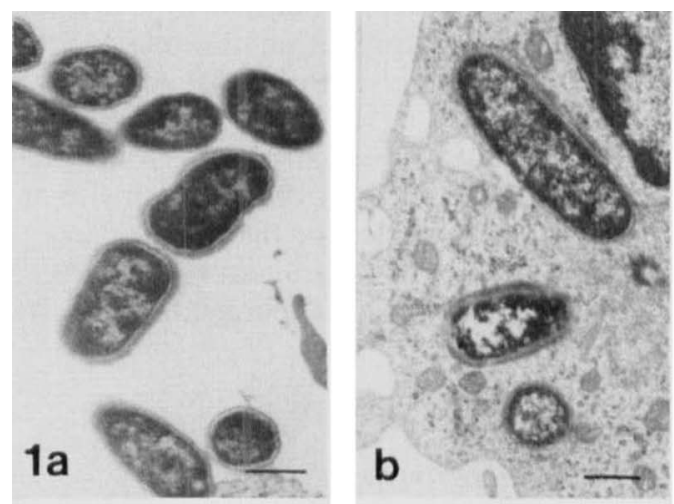

Preparation of peritoneal exudate cells for electronmicroscopy

The suspension of fixed PEC and extracellular bacteria was washed three times with $1.5 \mathrm{ml}$ of chilled cacodylate buffer by centrifugation and postfixed with $1 \%$ osmium tetroxide for $1 \mathrm{~h}$ at room temperature. After dehydration with increasing concentrations of ethanol, the PEC pellets were embedded in Polybed epoxy resin (Polysciences, Inc., Warrington, PA). Ultrathin sections were stained with uranyl acetate and Reynold's lead citrate. They were examined in a Hitachi HS-8 electronmicroscope.

\section{Results}

\section{Effect of bacterial challenge}

Intraperitoneal challenge with $2 \times 10^{7}$ salmonellae initiated a rapid dissemination of the pathogen throughout the reticuloendothelial system and resulted in progressive infection. Microscopic lesions were seen in the liver and spleen within $72 \mathrm{~h}$. Mice began to die $54 \mathrm{~h}$ after the infection.

\section{Sequence of intracellular destruction of salmonellae}

Soon after their ingestion by polymorphs and macrophages, there appeared to be two alternative sequences of destructive events of salmonellae by host phagocytes. The first was progressive cytoplasmic vacuolation followed by rupture of the bacterial envelope, and the second was an early distortion of the bacterial envelope and condensation of cytoplasmic granules. These changes are depicted in figs. 1 and 2. Fig. la shows the normal cytology of salmonellae in the extracellular environment of the peritoneal washings. Fig. lb shows a longitudinal and a transverse section of organisms shortly after

Fig. 1. a. Intact extracellular salmonellae in peritoneal washings. b-d. A sequence of bacterial degeneration within peritoneal phagocytes in which the injury begins in the bacterial cytoplasm. $\times 12000$; bar $=0.5 \mu \mathrm{m}$. 

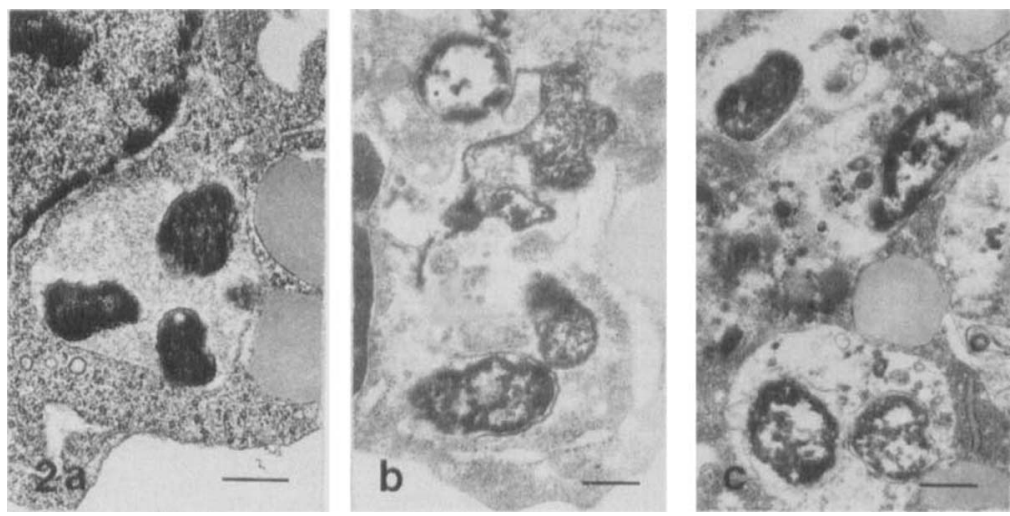

ig. 2. c. A sequence of bacterial degeneration within peritoneal phagocytes in which the injury begins in the bacterial envelope. : 12000 ; bar $=0.5 \mu \mathrm{m}$.

Igestion by a phagocyte but while still retaining leir cytological integrity. The third organism in the liddle of this phagocyte is undergoing an early age of cytological degeneration, characterized by tild central vacuolation (electron-lucent areas) and urly peripheral condensation of cytoplasmic graules. Then, as seen in fig. 1c, the degenerative rocess continues with a progressive enlargement and confluence of central vacuoles along with increasing peripheral margination of condensed cytoplasmic granules around the inside of an apparently intact bacterial envelope. Finally, the bacterial envelope becomes irregular and discontinuous, leading to rupture of the bacterium as shown in fig. 1d. Alternatively, the initial injury to the intracellular bacterium begins with the disruption of the

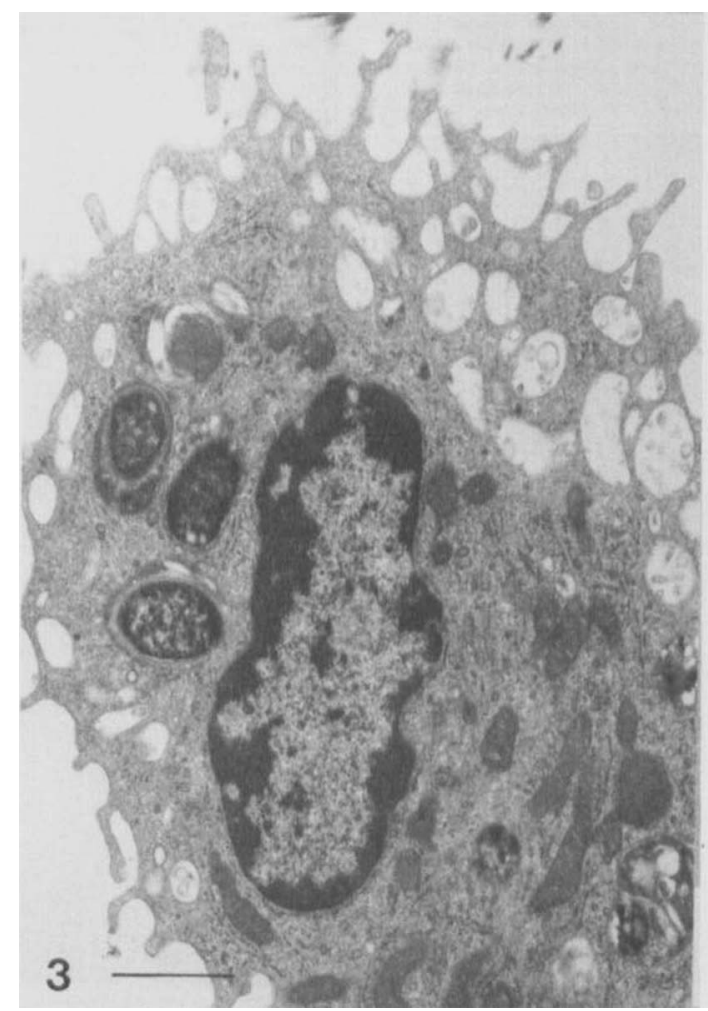

Fig. 3. A peritoneal macrophage $3 \mathrm{~h}$ after infection. $\times 12700 ; \mathrm{bar}=1.0 \mu \mathrm{m}$. 

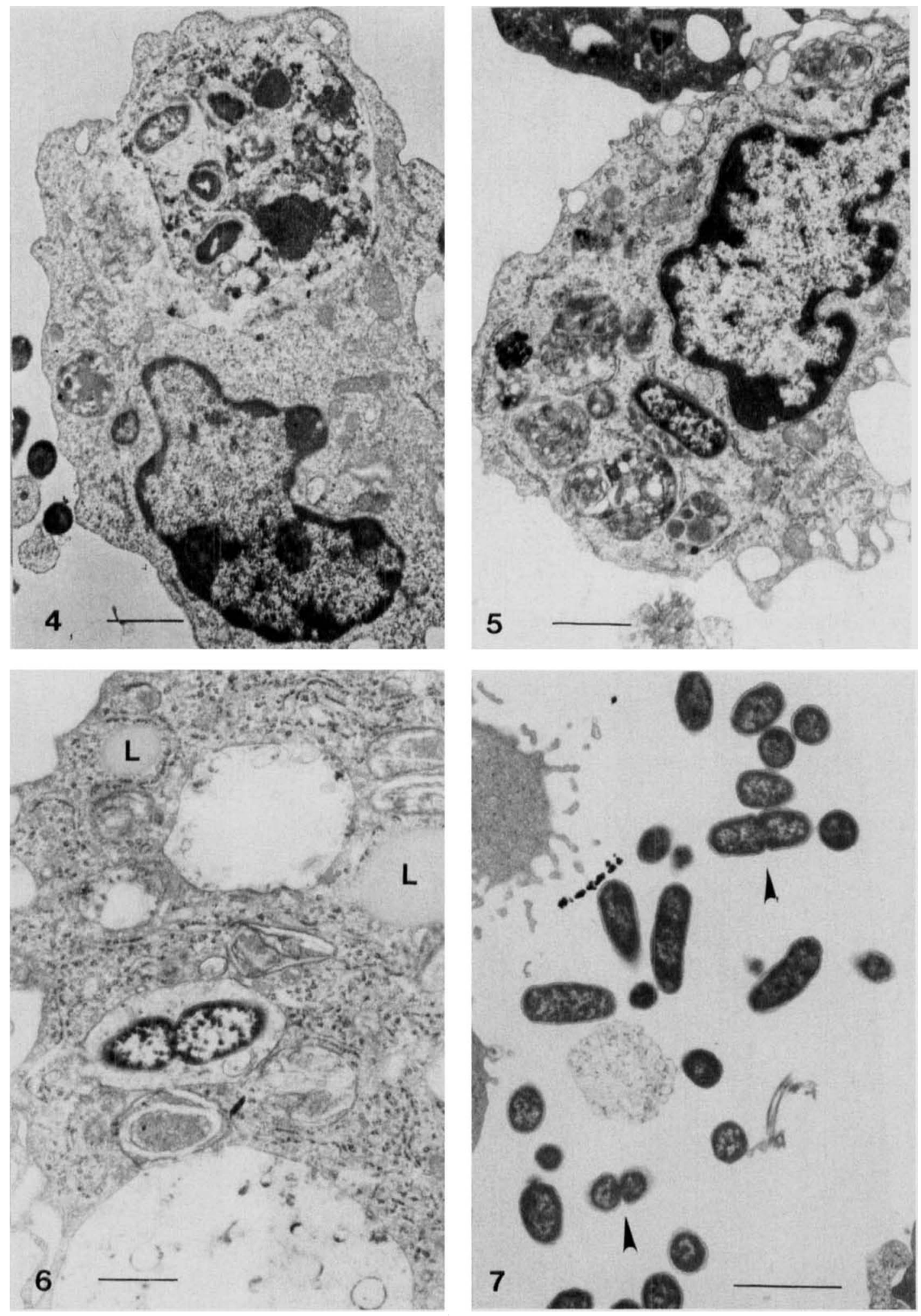

Figs. 4 and 5. Macrophages $7 \mathrm{~h}$ after infection, one of which contains a polymorph. $\times 12700 ;$ bar $=1.0 \mu \mathrm{m}$.

Fig. 6. Cytoplasm of a macrophage $24 \mathrm{~h}$ after infection. $\mathrm{L}=$ lipid droplet; $\times 12700 ; \mathrm{bar}=1.0 \mu \mathrm{m}$.

Fig. 7. Extracellular bacteria in peritoneal washings $24 \mathrm{~h}$ after infection. Arrows show bacteria undergoing division. $\times 17000$; bar $=1.0 \mu \mathrm{m}$. 

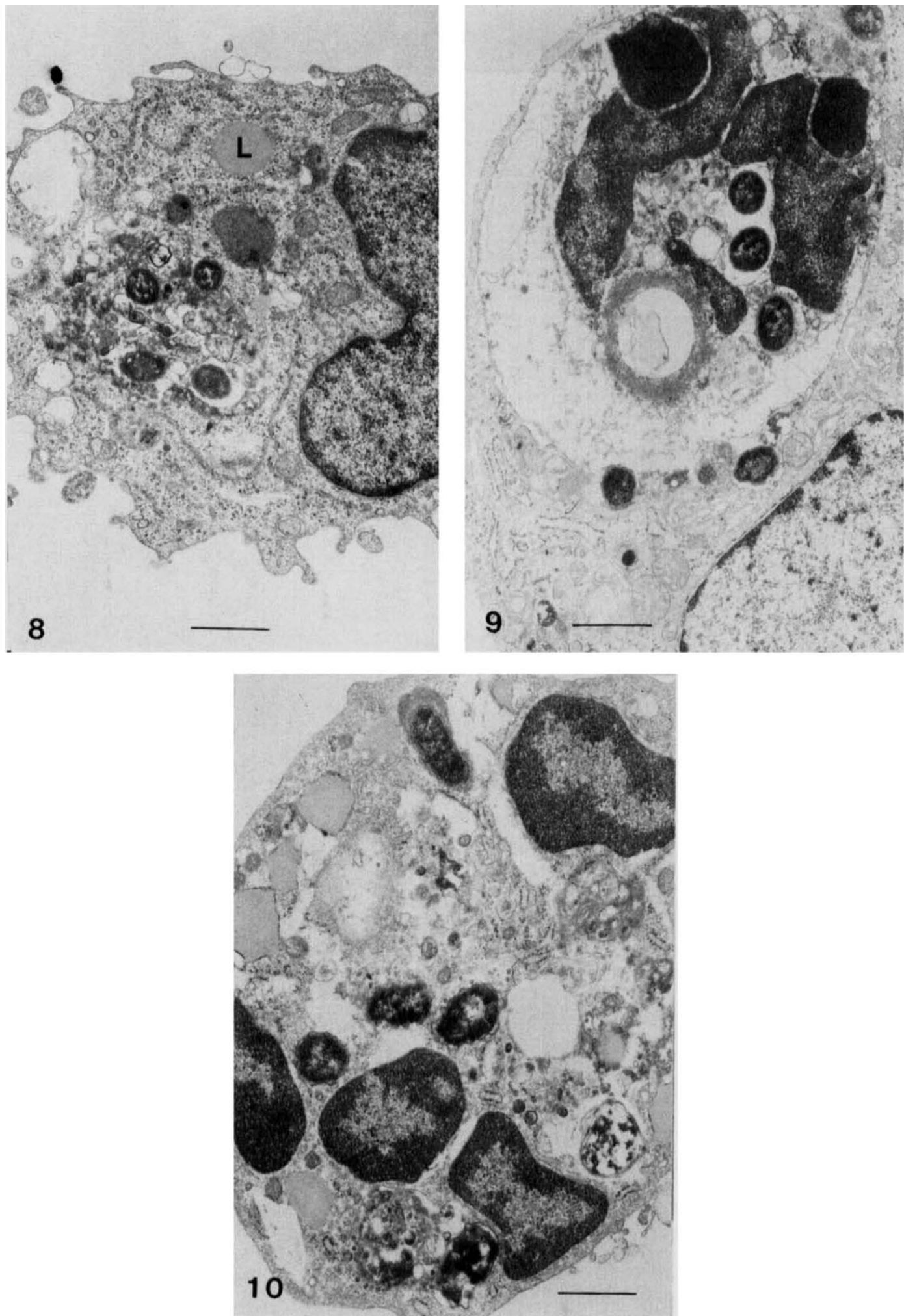

Fig. 8. A macrophage $30 \mathrm{~h}$ after infection. $\mathrm{L}=$ lipid droplet; $\times 12700$; bar $=1.0 \mu \mathrm{m}$.

Fig. 9. A macrophage after ingesting a polymorph $54 \mathrm{~h}$ after infection. $\times 12700$; bar $=1.0 \mu \mathrm{m}$.

Fig. 10. A polymorphonuclear leukocyte $54 \mathrm{~h}$ after infection. $\times 12700$; bar $=1.0 \mu \mathrm{m}$. 

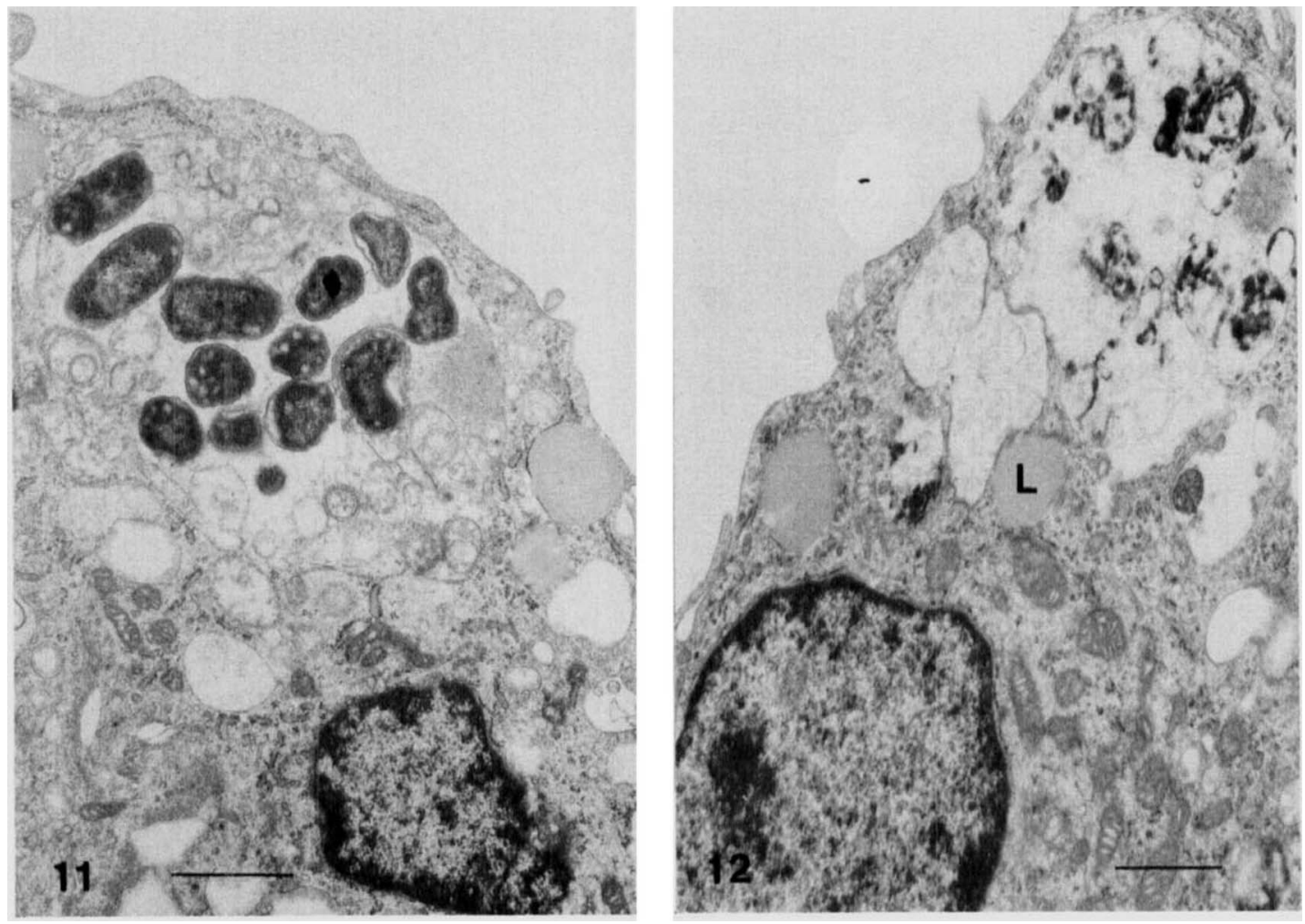

Figs. 11 and 12. Macrophages $72 \mathrm{~h}$ after infection. $\mathrm{L}=$ lipid droplet; $\times 12400$ and $\times 12700$, respectively; bar $=1.0 \mu \mathrm{m}$.

bacterial envelope and a diffuse condensation of the cytoplasmic granules as shown in fig. 2a. The bacterial morphology now appears compressed or shrunken and these bacteria disintegrate directly without complete disappearance of the cytoplasmic granules and vacuolation, as examplified by the bacteria in the lower portion of figs. $2 b$ and $2 c$.

\section{Cytological evidence for the destruction of salmonel- lae within phagocytes}

Figs. 3-12 are electronmicrographs taken from peritoneal washings of infected mice $3-72 \mathrm{~h}$ after infection. As early as $3 \mathrm{~h}$, some bacteria were ingested by phagocytes as seen in fig. 3 , which shows a macrophage soon after ingesting three bacteria whose cytological and morphological appearance remains intact. By $7 \mathrm{~h}$, there was evidence of active ingestion and digestion of the pathogen. For example, in fig. 4, the macrophage has apparently just phagocytosed one or two bacteria as well as a degenerating polymorph, which in turn contains several intracellular bacteria in various stages of digestion. The macrophage after $7 \mathrm{~h}$ (fig. 5) harbours one bacterium at an early stage of cytoplas- mic damage and several phagolysosomes containing what appears to be bacterial debris. The prominent ribosomes in the cytoplasm seen in fig. 6 are indicative of a macrophage which, at $24 \mathrm{~h}$, has ingested and digested foreign particles. Its phagolysosomes show the various stages of bacterial digestion, beginning with a pair of dividing bacteria at an early stage of fragmentation and ending with the formation of lipid droplets. The macrophage after $30 \mathrm{~h}$ (fig. 8) also contains several bacteria at various stages of digestion. Its lipid droplets suggest that this phagocyte has been active at the site for some time. Fig. 9 shows a macrophage after phagocytosis of a polymorph and fig. 10 shows a polymorph after $54 \mathrm{~h}$. Both phagocytes appear to be intact while the intracellular bacteria were in various stages of destruction by the host cells. The macrophage in this case has ingested bacteria and a polymorph which appears just to have engulfed three bacteria, one of which remains undamaged. The phagolysosome of the macrophage at $72 \mathrm{~h}$ (fig. 11) contains a large number of bacteria whose morphological integrity is distorted apparently after a relatively brief sojourn in the host cell. However, other evidence of bacterial debris and lipid droplets in the 
cytoplasm of this macrophage suggest that it may have been ingesting bacteria continuously for some time without suffering serious injury. The large phagolysosome in the macrophage after $72 \mathrm{~h}$ (fig. 12) contains an example of what may be the final recognisable stage of bacterial disintegration within host cells.

\section{Extracellular multiplication of salmonellae}

There was no evidence of bacterial multiplication within host phagocytes. Even when seemingly dividing bacteria were observed intracellularly, they appeared to be in various stages of degeneration (figs. Ic and 6). These pairs of organisms were probably phagocytosed while undergoing division. On the other hand, extracellular salmonellae could frequently be seen in the process of division (fig. 7).

\section{Discussion}

To resolve the issue of whether virulent salmonellae can survive and multiply within host phagocytes, experimental procedures must be designed in such a way that the fate of the intracellular bacteria can be determined within a population of phagocytes. Cell-culture methods have been used by many investigators for this purpose. Unfortunately, several pitfalls inherent in cell-culture procedures render the observations inconclusive at best. The major criticisms revolve around the quantitative methods by which the changing intracellular bacterial population is assayed, and, if antibiotics are incorporated into the culture medium to suppress the extracellular bacterial multiplication, their possible interference with the viability of intracellular bacteria. These technical concerns have frequently been discussed (Hsu and Radcliffe, 1968; Hsu \& Mayo, 1973; Rhodes and Hsu, 1974; Marecki et al. 1975).

In the present investigation, a relatively large dose $\left(2 \times 10^{7} \mathrm{cfu}\right)$ of virulent $S$. typhimurium was injected ip to initiate a rapidly progressive infection, such that inflammatory phagocytes, both polymorphs and macrophages, would swiftly accumulate at the site of challenge. This procedure was necessary to facilitate the early phagocytosis of bacteria by a relatively large proportion of the exudative cells so that intracellular bacteria could readily be examined by electronmicroscopy. This would allow the study on the interactions between individual inflammatory cells and salmonellae in situ at a very early stage of the infection and before the onset of acquired immunity. It should be emphasised that this study was not concerned with the process and pathology of the disease in the intact host, nor with the antibacterial action of resident peritoneal macrophages in the host. The fate of the pathogen in the intracellular versus the extracellular location of host tissues was determined by direct electronmicroscopic observation of the morphology of the bacteria. This procedure had the advantage of avoiding various criticisms, including the counting of intracellular bacteria, the possible effect of antibiotics on intracellular bacteria and the artificial nature of cell-culture procedures.

Several general observations can be made. Peritoneal exudative phagocytes derived from innately susceptible mice, both polymorphs and macrophages, were capable of ingesting virulent salmonellae as early as $3 \mathrm{~h}$ after infection in the absence of specific antibodies. However, in spite of the initial inoculation of a relatively large number $\left(2 \times 10^{7} \mathrm{cfu}\right)$ of the pathogen ip, each phagocytic cell appeared to have fewer than five bacteria in the sections examined. This is consistent with the previous observation that the pathogenicity of salmonellae is directly related to their antiphagocytic properties (Wells and Hsu, 1970; Hsu and Piper, 1972). It was also clear that the destruction of the ingested bacteria occurred rapidly, resulting in their complete disintegration. The sequence of degenerative changes of intracellular bacteria appeared to proceed either through cytoplasmic deterioration (figs. 1b-d) or through damage to the bacterial surface and distortion of its morphological structure (figs. 2a-c). Although most of the photomicrographs presented here show bacteria within macrophages, there was early inflammatory exudation of polymorphs into the peritoneal cavity, followed by a later influx of monocytes. Figs. 4 and 9 show that polymorphs were actively ingesting bacteria before their subsequent engulfment by macrophages.

The phagocytes at the site of infection displayed an ability to ingest and digest the pathogen continuously without incurring serious injury to themselves, as suggested by the observation that their cytoplasm frequently contained bacteria at various stages of disintegration (figs. 5, 8, 10 and 11). There was no indication of active intracellular bacterial multiplication, although it would be possible to see dividing bacteria in these fixed tissue preparations. Several dividing bacteria were seen undergoing intracellular disintegration (figs. $1 \mathrm{c}$ and 6 ) but these were presumably phagocytosed at the time of division. Furthermore, if virulent salmonellae did multiply within phagocytic leukocytes, it should be possible to see large numbers of intact intracellular bacteria in many host cells. This was not the case. In contrast, whenever a relatively large number of 
bacteria was seen within host cells, they had usually lost their structural integrity (fig. 11). Hence, in the absence of any evidence of intracellular bacterial multiplication, the rapid proliferation of salmonellae within the infected host must be attributed to their active extracellular replication as seen in fig. 7 .

The representative electronmicrographs in this study provide a clear illustration of both the intracellular destruction and extracellular multiplication of virulent $S$. typhimurium at the site of infection in mice. The magnification in electronmicroscopy shown here allows the morphological integrity of several bacteria to be seen within one frame, from which their viability or degeneration can be assessed. No attempt was made to describe the mechanism or process of bacterial disintegration by examining the ultrastructural detail of cytological components of individual bacteria. The fixation method used was considered adequate for the proper fixation of a suspension of single cells. It is reasonable to discount the possibility that fixation artifacts were misinterpreted as degenerative changes of intracellular bacteria because intact bacteria were seen adjacent to degenerating ones within the same phagocytes (figs. lb and 9). Since each tissue section represents a plane across the host cell amounting to less than $1 \%$ of the total spherical volumes of the whole cell, it would be impractical to determine the percentage of bacteria surviving or being destroyed within a phagocyte at a given time. In light of the electronmicroscopic evidence of intracellular killing of salmonellae in this study, the possibility that a few salmonellae might survive and multiply within host cells is rendered insignificant, because their contribution to the total increase in the bacterial population in host tissues would be negligible compared with the massive extracellular bacterial proliferation in the peritoneal cavity of infected mice.

The evidence presented here, therefore, lends further support to the previous work from this laboratory (Hsu and Mayo, 1973; Marecki et al., 1975; Mayo et al., 1977; Nakoneczna and Hsu, 1980 and 1983) which showed that salmonellae have erroneously been described as facultative intracellular bacteria (Suter and Ramseier, 1964; Collins, 1974). A thorough search of the literature reveals that there is no satisfactory experimental evidence to show unequivocably the survival or multiplication of virulent salmonellae within host macrophages. Histopathological evidence derived from lesions in the liver and spleen of infected mice (Nakoneczna and Hsu, 1980 and 1983) further demonstrates that the early stage of a primary lesion and of lesions in infected mice protected by killed salmonella vaccine is characterised by the rapid accumulation of polymorphs, not macrophages. Collectively, therefore, the classification of salmonellae as facultative intracellular bacteria is untenable. The pathogenic mechanism of this organism is directly related to its antiphagocytic property and hence its ability to proliferate in the extracellular location of host tissues.

This study was supported by the Grant-in Aid Program for the Faculty of Virginia Commonwealth University. Y-n.G. was a visiting scientist from the Department of Microbiology, Inner Mongolia Medical College, Huhehot, People's Republic of China. Her fellowship was funded by the Inner Mongolia Science and Technology Commission. PRC. Dolores A. Tessandori participated in a portion of this investigation under an $A$. D. Williams Summer Fellowship, 1982, School of Nursing, MCV/ VCU. The authors wish to thank the staff of the Electron Microscope Laboratory of the Department of Pathology, R. H. Freeman, Ethel T. Lovings, T. D. Lutz and Edwina W. Westbrook, for their technical and instructional assistance.

\section{REFERENCES}

Beckerdite S, Mooney C, Weiss J, Franson R, Elsbach P 1974 Early and discrete changes in permeability of Escherichia coli and certain other gram-negative bacteria during killing by granulocytes. Journal of Experimental Medicine 140:396409.

Briles D E, Lehmeyer J, Forman C 1981 Phagocytosis and killing of Salmonella typhimurium by peritoneal exudate cells. Infection and Immunity 33:380-388.

Carrol M E W, Jackett P S, Aber V R, Lowrie D B 1979 Phagolysosome formation, cyclic adenosine $3^{\prime}: 5^{\prime}$-monophosphate and the fate of Salmonella typhimurium within mouse peritoneal macrophages. Journal of General Microbiology 110:421-429.

Collins F M 1974 Vaccines and cell-mediated immunity. Bacteriological Review's 38:371-402.

Hsu H S. Mayo D R 1973 Interactions between macrophages of

guinea pigs and salmonellae. III. Bactericidal action and cytophilic antibodies of macrophages of infected guinea pigs. Infection and Immunity 8: 165-172.

Hsu H S, Piper V M 1972 Acquired resistance to and comparative virulence of Salmonella typhimurium demonstrated by cutaneous lesions in guinea pigs. Journal of the Reticuloendothelial Society 11, 343-357.

Hsu H S, Radcliffe A S 1968 Interactions between macrophages of guinea pigs and salmonellae. I. Fate of Salmonella typhimurium within macrophages of normal guinea pigs. Journal of Bacteriology 96:191-197.

Mackaness G B, Blanden R V, Collins F M 1966 Host-parasite relations in mouse typhoid. Journal of Experimental Medicine 124:573-583.

Marecki N M, Hsu H S, Mayo D R 1975 Cellular and humoral aspects of host resistance in murine salmonellosis. British Journal of Experimental Pathology 56: 231-243.

Mayo D R, Hsu H S, Lim F 1977 Interactions between 
salmonellae and macrophages of guinea pigs. IV. Relationship between migration inhibition and antibacterial action of macrophages. Infection and Immunity 18:52-59.

Mitsuhashi S, Sato I, Tanaka T 1961 Experimental salmonellosis. Intracellular growth of Salmonella enteritidis ingested in mononuclear phagocytes of mice and cellular basis of immunity. Journal of Bacteriology 81:863-868.

Modrzakowski M C, Spitznagel J K 1979 Bactericidal activity of fractionated granule contents from human polymorphonuclear leukocytes: antagonism of granule cationic proteins by lipopolysaccharide. Infection and Immunity 25:597-602.

Nakoneczna I, Hsu H S 1980 The comparative histopathology of primary and secondary lesions in murine salmonellosis. British Journal of Experimental Pathology 61:76-84.

Nakoneczna I, Hsu H S 1983 Histopathological study of protective immunity against murine salmonellosis induced by killed vaccine. Infection and Immunity 39:423-430.

Rest R F, Cooney M H, Spitznagel J K 1978 Bactericidal activity of specific and azurophil granules from human neutrophils: studies with outermembrane mutants of Salmonella typhimurium LT-2. Infection and Immunity 19:131-137.
Rhodes M W, Hsu H S 1974 The effect of kanamycin on the fate of Salmonella enteritidis within cultured macrophages of guinea pigs. Journal of the Reticuloendothelial Society 15:112.

Sato I, Tanaka T, Saito K, Mitsuhashi S 1962 Inhibition of Salmonella enteritidis ingested in mononuclear phagocytes from liver and subcutaneous tissue of mice immunized with live vaccine. Journal of Bacteriology 83:1306-1312.

Suter E, Ramseier H 1964 Cellular reactions in infection. Advances in Immunology 4:117-173.

van Zwet T L, Thompson J, van Furth $R 1975$ Effect of glucocorticosteroids on the phagocytosis and intracellular killing by peritoneal macrophages. Infection and Immunity 12:699-705.

Wells P S, Hsu H S 1970 Interactions between macrophages of guinea pigs and salmonellae. II. Phagocytosis of Salmonella typhimurium by macrophages of normal guinea pigs. Infection and Immunity 2:145-149. 